Community Composition of Bacterial Biofilms Formed on Simple Soil Based Bioelectrochemical Cell Anodes and Cathodes

David B. Ringelberg, Karen L. Foley,

April 2012

and Charles M. Reynolds 


\section{Community Composition of Bacterial Biofilms Formed on Simple Soil Based Bioelectro- chemical Cell Anodes and Cathodes}

David B. Ringelberg, Karen L. Foley, and Charles M. Reynolds

Cold Regions Research and Engineering Laboratory

U.S. Army Engineer Research and Development Center

72 Lyme Road

Hanover, NH 03755

Final report

Approved for public release; distribution is unlimited.

Prepared for U.S. Army Corps of Engineers

Washington, DC 20314-1000

Under Installation Technology Program 


\section{Abstract:}

Microbial fuel cells (MFC), as bioelectrochemical systems, hold promise as a sustainable source of energy for use in novel environments and settings. Although electrode biofilms, both anode and cathode, are critical to the production of power in these systems, the taxonomies of the biofilms that form are not fully understood. The specific objectives of the current study were to classify the bacteria that enriched onto fuel cell electrodes, with three biogeochemically distinct surface soils serving as the inocula. Following 1000 hours of incubation under saturated soil conditions, the community composition of the anode and cathode bacterial biofilms was quantified by culture, fatty acid profile (FA), and terminal restriction fragment length polymorphisms (TRFLP). The three soils produced open circuit voltages of between 60 and $120 \mathrm{mV}$, but only one soil maintained voltage under resistance $(60 \mathrm{mV}$ at $10,000 \Omega)$. Fatty acid profiling identified differences among anode, cathode, and bulk soil microbial communities, specifically a greater relative abundance of terminally branched saturated FA in the bulk soils and a greater relative abundance of monounsaturated and cyclopropane FA on electrode surfaces. Bacteria cultured from both the anode and cathode biofilms included species of Actinobacteria; however, only the anode biofilms produced species of Firmicutes and Proteobacteria. Analysis of TRFLP profiles putatively identified a diversity of bacteria in the biofilms recovered from both electrode surfaces. The most predominant organisms detected were the $\alpha$ - and $\beta$-Proteobacteria, specifically the Rhizobiales, Rhodobacterales, and Burkholderiales. Although the detection of similar community fingerprints on both anodes and cathodes was not anticipated, the diversity of organisms putatively identified indicated a complexity that would support a coupled nitrogen cycle, one capable of facilitating the transfer of electrons to the soil cell anodes and from the soil cell cathodes.

DISCLAIMER: The contents of this report are not to be used for advertising, publication, or promotional purposes. Citation of trade names does not constitute an official endorsement or approval of the use of such commercial products. All product names and trademarks cited are the property of their respective owners. The findings of this report are not to be construed as an official Department of the Army position unless so designated by other authorized documents.

DESTROY THIS REPORT WHEN NO LONGER NEEDED. DO NOT RETURN IT TO THE ORIGINATOR. 


\section{Table of Contents}

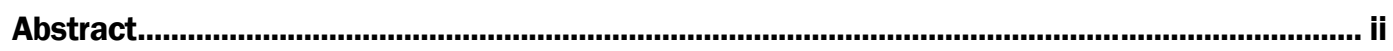

List of Figures and Tables .................................................................................................. iv

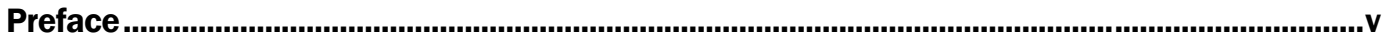

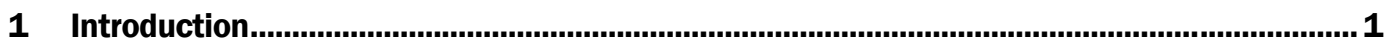

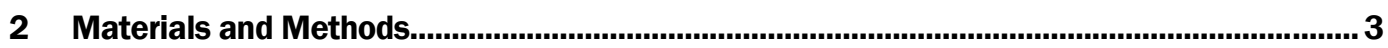

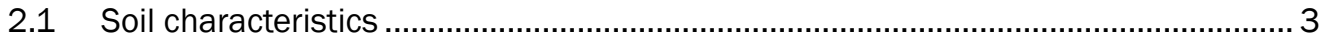

2.2 Bioelectrochemical Cells ................................................................................... 4

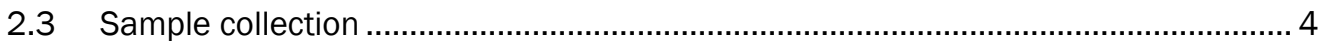

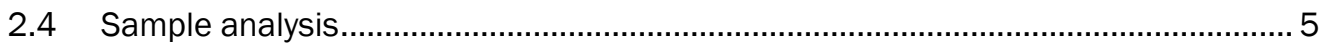

2.4.1 Culturable bacteria ......................................................................................... 5

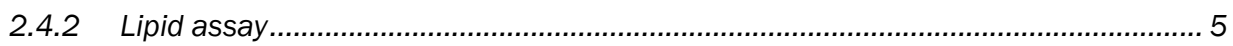

2.4.3 Terminal restriction fragment length polymorphisms (TRFLP)................................. 6

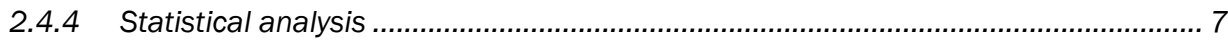

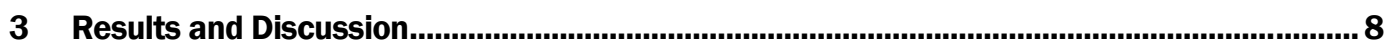

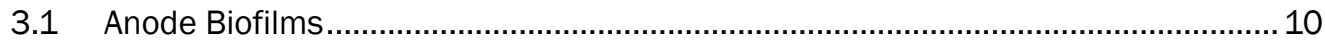

3.2 Cathode Biofilms ........................................................................................... 19

4 Summary and Conclusion...................................................................................................22

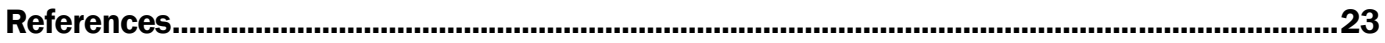

Report Documentation Page 


\section{List of Figures and Tables}

\section{Figures}

Figure 1. Actual soil cells with associated schematics.................................................................. 4

Figure 2. Voltage, open circuit potential, measured from the three soil cells over a 100 hour period.

Figure 3. 2D plot illustrating results from the extraction of the $1^{\text {st }}$ two principal components from a dataset comprised of arcsine square root transformed fatty acid molar percentages..

Figure 4. A means comparison of fatty acid methyl ester (FAME) structural class molar percentages ( $\mathrm{mol} \%$ ) across the averaged soil profiles (top, middle and bottom, $\mathrm{n}=9$ ), anode attached soils and biofilms $(n=5)$, cathode biofilms $(n=3)$, and catholyte $(n=2)$.

Figure 5. Recovered and retained terminal restriction fragments (TRF) for each of the three soil cells (FG, FW, and CRL) following three restriction digests (Hha I, Msp I, and Rsa I) of bacterial 16S rRNA amplicons of electrode (anode and cathode) biofilm DNA. .

Figure 6. Pie charts of each of the three soil cell anode and cathode biofilm terminal restriction fragments that could be putatively identified through an in silico digest of the ribosomal database.

\section{Tables}

Table 1. Geochemical characteristics are provided for each soil used to fill the anodic chamber of the three test fuel cells.

Table 2. Relative molar percentages and absolute abundances of prokaryotic and eukaryotic fatty acid (FA) biomarkers detected in the soils, top middle and bottom fractions, on the electrodes, biofilm and attached soil, and in the catholyte of the three test cells are provided.

Table 3. Factor variable correlations (loadings) between prokaryotic fatty acid (FA) profiles and the $1^{\text {st }}$ principal component that resulted following the principal components analysis of soil, electrode, and catholyte arcsine square root transformed fatty acid molar percentages.

Table 4. Putative identifications for retained terminal restriction fragments of amplified $16 S$ rRNA DNA recovered from the anodes and cathodes of the three test cells following the in silico digest of the ribosomal database.

Table 5. Enriched, isolated, and identified bacteria recovered from the anode and cathode biofilms of each of the three test cells. 


\section{Preface}

The work was performed by David B. Ringelberg, Karen L. Foley, and Dr. Charles M. Reynolds (Biogeochemical Sciences Branch, Terrence M Sobecki, Chief), U.S. Army Engineer Research and Development Center-Cold Regions Research and Engineering Laboratory (ERDC-CRREL). At the time of publication, Dr. Justin Berman was Chief of the Research and Engineering Division. The Deputy Director of ERDC-CRREL was Dr. Lance Hansen, and the Director was Dr. Robert Davis.

The use of trade, product, or firm names in this report is for descriptive purposes only and does not imply endorsement by the U.S. Government. The tests described and the resulting data presented herein, unless otherwise noted, were obtained from research conducted under the Installation Technology Program of the U.S. Army Corps of Engineers by the USAERDC. Permission was granted by the Chief of Engineers to publish this information. The findings of this report are not to be construed as an official Department of the Army position unless so designated by other authorized documents.

COL Kevin J. Wilson was the Commander and Executive Director of ERDC, and Dr. Jeffery P. Holland was the Director. 


\section{Introduction}

In 1912, Michael Potter identified an electrical effect that accompanied the microbial decomposition of organic matter. Although the ability of bacteria to catalyze the conversion of organic matter into electricity has been known for over 75 years, the use of bacteria in fuel cells to generate appreciable electrical power is a more recent occurrence. In 2003, Chaudhuri and Lovely were able to show that a novel bacterium, Rhodoferax ferrireducans, could transfer electrons directly to a graphite electrode while oxidizing a carbon substrate. The organism derived energy for growth and produced electricity from the coupled process. Rabaey et al. (2004) then demonstrated that microbial fuel cell (MFC) anodes can enrich for anodophyllic communities that form biofilms capable of selfmediating electron transfer, resulting in stable and long term power densities. Soluble redox mediators or electron shuttles have been identified that facilitate electron transfer to fuel cell anodes (Rabaey et al. 2005) and, as it turns out, the electron shuttles produced by one bacterium can be utilized by other species of anodic bacteria (Pham et al. 2008). Certain bacteria have also been shown to produce conductive pilus-like structures, nanowires that enable a direct transfer of electrons from cell membrane to the anode surface (Reguera et al. 2005). That bacteria are capable of colonizing MFC electrodes and that they possess the molecular traits to enable electron transfer to these electrodes has been established. Research is now focusing on the breadth of anodophyllic bacteria and microbes that exist in nature and into the factors that regulate electron transfer mechanisms.

The large percentage of studies examining bioelectrochemical system (BES) performance have focused on sewage sludge and wastewater as bacterial inocula, where anaerobic growth within the anodic chamber produces the electrons that when reduced at the cathode result in lower wastewater CODs (Alterman et al. 2006). Recent studies have begun looking into the nature of these biofilms in terms of community taxonomy and the activity related to electron transfer and power production. A number of studies have identified the Proteobacteria, including members of the alpha, beta, gamma, and delta classes, as being prominent anodophyllic organisms (Kim et al. 2004; Phung et al. 2004; Kim et al. 2007; Chung and Okabe 2009). Molecular analyses, specifically of the $16 \mathrm{~S}$ rRNA eubacterial gene, have also identified the presence of Firmicutes and Actinobacteria 
on wastewater enriched anodes (Chung and Okabe 2009; Phung et al. 2004, respectively).

Of growing interest is the performance of MFC under aerobic conditions. Traditional BES used a two-chamber system where bacteria in an anode compartment were separated from the cathode compartment by a polymeric proton exchange membrane (PEM). Many of these MFC used aqueous cathodes with oxygen supplied via air sparging. Advances in design demonstrated that BES employing air-cathodes and the absence of a PEM were still efficient and effective at generating electricity (Liu and Logan 2004). In addition, these forms of BES were less costly and amenable to aerobic applications, such as in riverine systems. Acknowledgement of military as well as commercial uses of MFC for continued surveillance systems or for powering environmental sensors has lead to developments in the miniaturization of BES. Novel designs have been used to minimize anode cathode distances and to take advantage of $3 \mathrm{D}$ electrode materials to significantly increase electrode surface areas (Shantaram et al. 2005; Ringeisen et al. 2006).

Although the interaction between an anode and a microbial biofilm is a critical component of any bioelectrochemical system, microbe facilitated electron transfer off of fuel cell cathodes can also play an integral role. The reduction of $\mathrm{O}_{2}$ at the cathode is often a significant bottleneck in BES efficiency and chemical catalysts, such as platinum, pyrolyzed iron, pthalocyanine, and cobalt tetramethylphenylporphrin, have all been used successfully to facilitate $\mathrm{O}_{2}$ reduction. However, Clauwaert et al. (2007) showed that bacteria can also facilitate the $\mathrm{O}_{2}$ reduction on the cathode surface and the formation of a cathode microbial biofilm, i.e., a biocathode, has appeal in terms of BES performance in terms of cost savings and improved power sustainability.

Microbial fuel cells as bioelectrochemical systems hold promise as a sustainable source of energy for use in novel ways and in novel environments. Metagenomics studies of anodic biofilms have and will likely continue to shed new light on the breadth of community functional dynamics that BES systems are capable of supporting (Liu et al. 2010). In this study we describe the molecular trait of three different soil based bioelectrochemical systems. We provide a polyphasic taxonomic description of the anodic and cathodic bacterial biofilms and identify common characteristics for use as a base for further development and refinement of BES for use in terrestrial environments. 


\section{Materials and Methods}

\subsection{Soil characteristics}

Characteristics of the three soils examined in the study are provided in Table 1. Two of the study soils, abbreviated FG and FW, were collected from areas outside of Anchorage, AK, and the third soil, abbreviated CRL, was collected from the Cold Regions Research and Engineering Laboratory, Hanover, NH. The soils were all air dried, sieved to $4.75 \mathrm{~mm}$ (FG and FW soils) and $2.00 \mathrm{~mm}$ (CRL soil) and stored at room temperature. Prior to introduction into the bioelectrochemical cells, each soil was brought to 0.33 bar moisture content and incubated at room temperature for 72 hours.

Table 1. Geochemical characteristics are provided for each soil used to fill the anodic chamber of the three test fuel cells.

\begin{tabular}{|c|c|c|c|c|}
\hline & & Fairbanks, AK USA & Fairbanks, AK USA & Hanover, NH USA \\
\hline $\mathrm{pH}$ & & FW & FG & CRL \\
\hline soluble salts & mmhos/cm & 7.8 & 5.6 & 6.5 \\
\hline $\mathrm{CEC}$ & $\mathrm{meq} / 100 \mathrm{~g}$ & 16.6 & 0.13 & 0.18 \\
\hline $\mathrm{TOC} / \mathrm{O} . \mathrm{M}$. & $\%$ & 1.4 & 2.3 & 2.7 \\
\hline $\mathrm{NO}_{3}-\mathrm{N}$ & $\mathrm{ppm}$ & 6.0 & 11.1 & 2.5 \\
\hline $\mathrm{NH}_{4}-\mathrm{N}$ & $\mathrm{ppm}$ & 6.3 & 7.8 & 2.4 \\
\hline $\mathrm{N}_{\mathrm{C}}$ ratio & $\mathrm{NH} / \mathrm{TOC}$ & 4.6 & $<3.9$ & 5.1 \\
\hline & & & 0.4 & 2.0 \\
\hline $\mathrm{P}$ & $\mathrm{ppm}$ & 4.4 & & \\
\hline $\mathrm{K}$ & $\mathrm{ppm}$ & 39 & 0.8 & 2.2 \\
\hline $\mathrm{Ca}$ & $\mathrm{ppm}$ & 1345 & 16 & 57 \\
\hline $\mathrm{Mg}$ & $\mathrm{ppm}$ & 97 & 294 & 533 \\
\hline $\mathrm{Fe}$ & $\mathrm{ppm}$ & $\mathrm{nd}$ & 97 & 40 \\
\hline $\mathrm{Mn}$ & $\mathrm{ppm}$ & $\mathrm{nd}$ & 3.5 & 0.6 \\
\hline $\mathrm{Cu}$ & $\mathrm{ppm}$ & $\mathrm{nd}$ & 8.1 & 1.2 \\
\hline $\mathrm{Zn}$ & $\mathrm{ppm}$ & 3.8 & 0.0 & 0.0 \\
\hline Texture & & sandy loam & 0.2 & 1.2 \\
\hline sand & $\%$ & 49 & 29 & 49 \\
\hline silt & $\%$ & 46 & 60 & 44 \\
\hline clay & $\%$ & 5 & 12 & 7 \\
\hline & & & & \\
\hline $\mathrm{nd}$ & & & & \\
\hline not detected & & & & \\
\hline & & & & \\
\hline
\end{tabular}




\subsection{Bioelectrochemical cells}

A schematic of the bioelectrochemical cells is provided in Figure 1. Each cell consisted of an anodic chamber filled with soil and separated from the surrounding cathodic chamber by a cation exchange membrane (CMI$7000 S$, Membranes International, Inc.). The cation exchange membrane was sealed to the bottom of the glass jar with paraffin wax $(\sim 2 \mathrm{~cm}$ height). Each chamber, anode and cathode, contained a graphite electrode of equal dimensions, $3 \mathrm{~mm}$ deep $\times 5 \mathrm{~mm}$ wide $\times 100 \mathrm{~mm}$ long. The anodic chamber was loaded with $\sim 5 \mathrm{~g}$ of soil, tamped, the electrode placed in the center, another $5 \mathrm{~g}$ of soil added and tamped around the electrode, etc., until the chamber was filled to within 1-2 $\mathrm{mm}$ of the top. The cathodic chamber was filled with deionized sterile water and continuously sparged with air. The electrode was then suspended in the water between the glass jar and the CEM. A small portion of the anodic soil, $\sim 0.1 \mathrm{~g}$, was added to the cathodic water as inocula. Voltage was measured across the two electrodes every hour using a digital multimeter (Kiethly Instruments) either as an open voltage or across a $10,000 \Omega$ resistor.
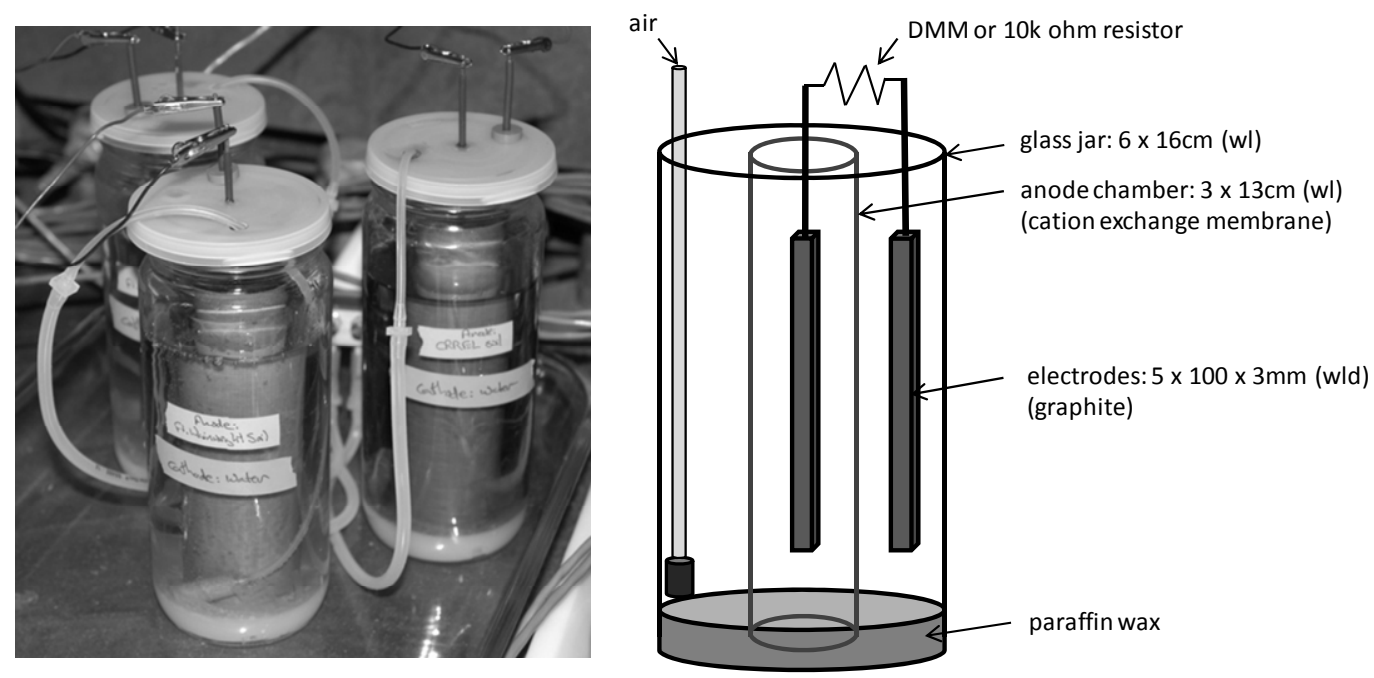

Figure 1. Actual soil cells with associated schematics.

\subsection{Sample collection}

Each BES cell was sampled to obtain taxonomic descriptions of the electrode biofilms and the surrounding media, i.e., soil or water. Although in some instances, sufficient material was not obtained for a particular assay, the sampling scheme outlined below was followed for each cell. Anode electrodes were first pulled from the soil columns and tapped gently to remove loosely attached soil clumps. The electrodes were then dipped in 
sterile milli-Q water to recover the attached soils (AS), which were then collected by centrifugation at 8400 rpm for 20 minutes. The supernatant was decanted and the soils resuspended in $2 \mathrm{~mL}$ of sterile water for subsequent assay of lipids ( $0.8 \mathrm{~mL}$ ), nucleic acids $(0.8 \mathrm{~mL})$, and culturable cells (0.4 mL). Biofilms remaining on electrodes were then recovered by swabbing each side with separate $5^{-} \times 5^{-} \mathrm{mm}$ sections of autoclaved $(15 \mathrm{~min}$. at $5.7 \mathrm{kPa}$ ) glass fiber filter paper (GF/A Whatman). One third of each swab was removed, suspended in $2 \mathrm{~mL}$ of sterile water and vortexed vigorously before removing 0.2-mL aliquots for cell culture. The remaining swabs were then directly assayed for either lipids or nucleic acids. Anode soils were separated into three sections, top, middle, and bottom, and mixed using a spatula before aliquots were removed to assay for lipids ( $2 \mathrm{~g}$ ) and nucleic acids ( $0.2 \mathrm{~g})$. Both the catolyte solution and the cathode electrodes were then sampled. Cells were recovered from the catholyte by centrifuging $30 \mathrm{~mL}$ at $9400 \mathrm{rpm}$ for 20 minutes. The cell pellets were then resuspended in $1.6 \mathrm{~mL}$ of sterile milli-Q water and $0.8 \mathrm{~mL}$ was removed for determining lipid content and $0.8 \mathrm{~mL}$ for determining nucleic acid content. Cathode electrodes were processed in the same manner as the anode electrodes, excluding the step of dipping the electrode in sterile milli-Q water. Culture for bacterial isolation was not performed on either the catholyte solution or the anode soils.

\subsection{Sample analysis}

\subsubsection{Culturable bacteria}

Serial dilutions of each 0.2-0.4 mL aliquot was spread plated onto PTYG agar [5 g Peptone, $5 \mathrm{~g}$ tryptone, $5 \mathrm{~g}$ yeast extract, $10 \mathrm{~g}$ glucose, $0.6 \mathrm{~g}$ $\mathrm{MgSO}_{4}{ }^{*} 7 \mathrm{H}_{2} \mathrm{O}$, $0.06 \mathrm{~g} \mathrm{CaCl}_{2}{ }^{*}{ }_{2} \mathrm{H}_{2} \mathrm{O}$ per $1 \mathrm{~L}$ water at $\mathrm{pH}$ 7.0] and $\mathrm{R} 2 \mathrm{~A}$ agar (Difco, Becton Dickinson). Following 48 hours of incubation at $25^{\circ} \mathrm{C}$, single colonies were picked and re-streaked for isolation. Isolated colonies were then identified by fatty acid profiles using the Microbial Identification System (MIDI Inc.) using Sherlock v4.0 software.

\subsubsection{Lipid assay}

In situ fatty acid profiles were obtained from the bulk anode soils, the cathode waters, and the anode and cathode electrode swabs. Briefly, total lipids were extracted from sample materials in a volume of chloroform:methanol:phosphate buffer $\left(50 \mathrm{mM} \mathrm{PO}_{4}\right.$ at $\mathrm{pH} 7.4$ ) in the ratios of 1:2:0.8 (v:v:v) (White and Ringelberg 1998). Soils, $2 \mathrm{~g}$, and filter papers 
were extracted in $3.8 \mathrm{~mL}$ of the extractant. For the catholyte and loosely attached soils, $0.8 \mathrm{~mL}$ of the suspensions was used in place of the $50 \mathrm{mM}$ $\mathrm{PO}_{4}$ buffer. Following phase separation and recovery of total lipids, a strong acid methanolysis was used to form fatty acid methyl esters (FAME), which were then recovered in a volume of hexane:chloroform $(4: 1, v: v)$. The FAME were then further separated, quantified, and identified by gas chromatography/mass spectrometry. Methyl nonadecanoate, $50 \mathrm{pmol} \mu \mathrm{L}^{-1}$ was used as an internal standard and individual fatty acids were expressed on a mole per gram basis. The relative molar percentage of each fatty acid was used for statistical comparisons.

\subsubsection{Terminal restriction fragment length polymorphisms (TRFLP)}

Total nucleic acids were recovered from the anode filter paper swabs using the PowerPlant ${ }^{\mathrm{TM}}$ DNA Isolation Kit (Mo Bio Laboratories). A Precellys 24 homogenizer (Bertin Technologies) was used to facilitate cell lysis. The primer pair 27F-FAM (5' - FAM- aga gtt tga tcc tgg ctc ag - 3') and 926R $\left(5^{\prime}-\right.$ ccg tca att cet ttr agt $t t-3$ ') was used to amplify a $16 \mathrm{~S}$ rDNA fragment of approximately $915 \mathrm{bp}$ in length. Approximately 100-200 ng of the amplicon was then purified on a QiaQuick PCR purification spin column (Qiagen) before digestion with $5 \mathrm{U}$ of the restriction enzymes HhaI, MspI and RsaI at $37^{\circ} \mathrm{C}$ for 3 hours. Enzyme activity was stopped by heating at $60^{\circ} \mathrm{C}$ for 30 minutes. The digested amplicons were then desalted on Qiaquick nucleotide removal spin columns (Qiagen) and the concentrations adjusted to approximately $100 \mathrm{ng} \mu \mathrm{L}^{-1}$. Purified fragments were then separated by capillary electrophoresis (15-s injection time at $15 \mathrm{kV}, 15 \mathrm{kV}$ electrophoretic voltage for $45 \mathrm{~min}$.) on an Applied Biosystem 310 genetic analyzer. Fragments were sized against an x-rhodamine labeled $1000 \mathrm{bp}$ ladder (MapMarker 1000, Bioventures, Inc.) using the local southern method within Peak Scanner software (v1, Applied Biosystems). Resulting TRF profiles were post-processed following the outline of Dunbar et al. (2000). TRF area percentages were then imported into the MICA $3 \mathrm{~T}$ RFLP analysis (PAT+) program to perform in silco digests of the ribosomal database (release 10 update 12) of good quality $16 \mathrm{~S}$ rRNA fragments (Shyu et al. 2007). Identifications resulting from each digest were compared using the on-line software program VENNY (Oliveros 2007) to produce putative identifications at the phylum, class, and order levels. 


\subsubsection{Statistical analysis}

Principal components analysis was performed on arcsine square root transformed fatty acid molar percentages (Statistica v8). Means comparisons was by Tukey honest significant difference via a post hoc analysis and significance assumed at a $\mathrm{p}<0.05$. 


\section{Results and Discussion}

The primary purpose of the simple soil cells was to facilitate anodic colonization by the extant soil bacteria. To date, there have been few efforts investigating soils as potential anode inocula (Schamphelaire et al. 2008; Schamphelaire et al. 2010; Ishii et al. 2008a,b; Jiang et al. 2010). The intent of this study was to augment these investigations by providing a polyphasic description of biofilms enriched onto graphite electrodes. Soils are non-ideal environments for MFC operation primarily because of the presence of the preferred electron acceptor oxygen and to existing constraints to mass transport. To lessen the negative impacts of these conditions, we brought the soils to near saturation with water. By doing so we hoped to facilitate electron transfer via soluble redox mediators and bacterial access to available soluble nutrients in the soils. In addition, we postulated that the near saturated soil conditions would favor biofilm formation and, once formed, these biofilms would exhibit a redox gradient that was increasingly negative from the outside in (Bishop and Yu 1999).

As the cells were not flow through and there was no active transport of carbon or nutrients to the anode electrode surface, we assumed that only the soil microbes in proximity to the anode electrode would be enriched to form an anode biofilm. By filling the anode chamber with sieved and homogenized soil mixtures, impacts from natural soil heterogeneity in terms of microbial diversity were reduced. By collecting the loosely attached anode soil in addition to the direct anode bioflm, we intended to recover both the enriched and the enriching bacterial populations. With regards to the cathodic chamber, no salt was added to the catholyte solution, which is typically done to facilitate electron reduction at the cathode. This choice was made to minimize the likelihood of selective enrichment of halophilic organisms. Although the construction and imposed experimental conditions of each soil cell were non-ideal in terms of power production, the potential for electricity was not fully impeded and obtaining an electrical current was crucial to establishing that the enriched electrode biofilms were at least partially electrogenic in nature. 


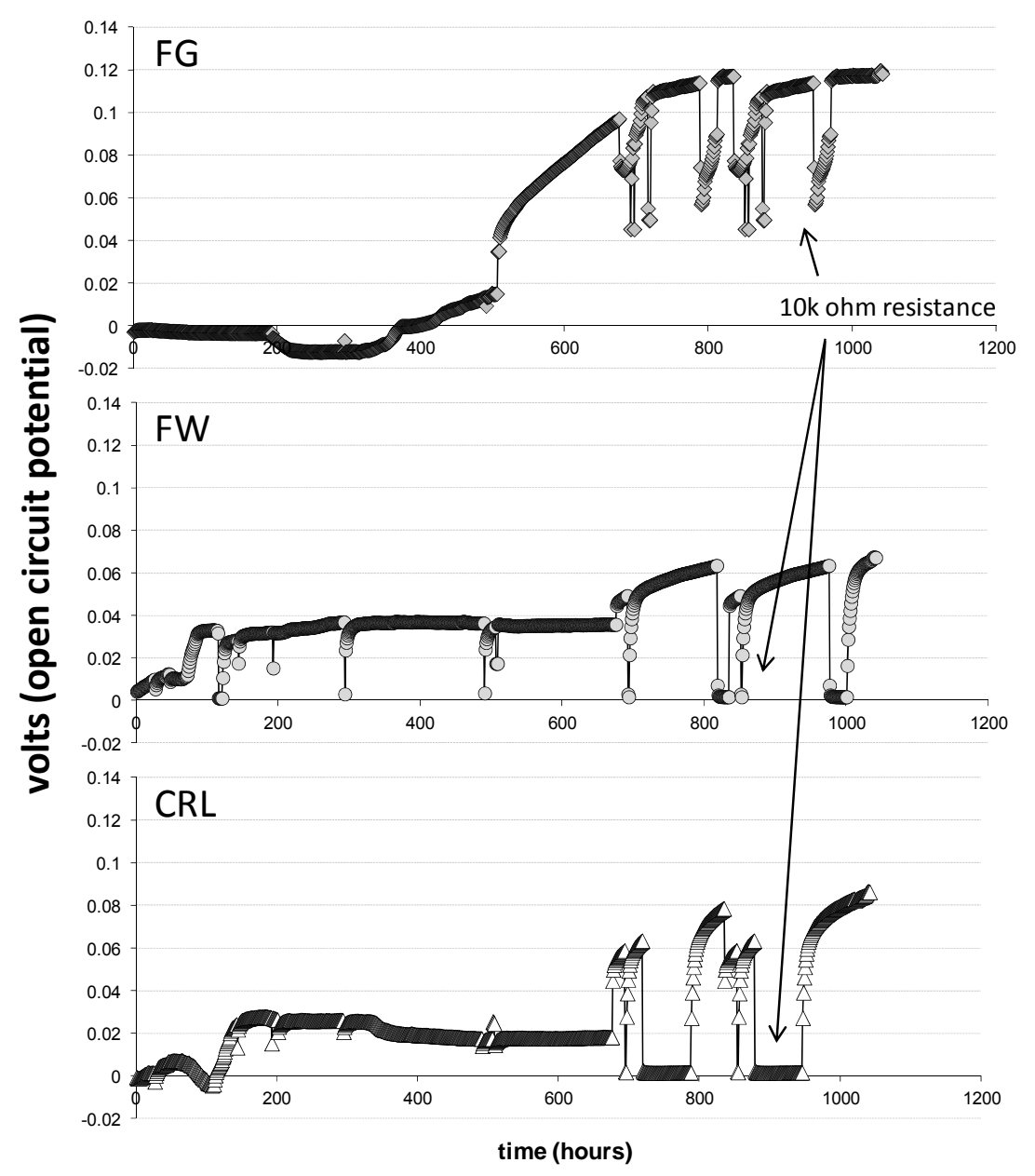

Figure 2. Voltage, open circuit potential, measured from the three soil cells over a 100 hour period. The sharp voltage declines indicate points in time where the output was measured across a $10-\mathrm{k} \Omega$ resistor

Results showed all three fuel cells produced electricity. Open circuit potentials (OCP) of between 60 and $120 \mathrm{mV}$ were recorded following an incubation period of 42 days (Fig. 2). Although these voltages were 6 to 110 times less than those recorded from a more efficient soil seeded MFC (Jiang et al. 2010), the increasing and sustained voltages suggested successful bacterial colonization of the embedded graphite anodes. Placing a small load, $10,000 \Omega$, onto each soil cell had a large effect on the voltage output from each cell, with only the FG cell exhibiting a measurable current of approximately $5 \mu \mathrm{A}$. This soil differed substantially from the other two soils in terms of total organic carbon content, which was five times greater, and iron and manganese content, which were five to eight times greater, respectively (Table 1). In addition, the $\mathrm{pH}$ of the FG soil, at 5.6, was substantially lower than that of either the CRL, 6.5, or FW soil, 7.8. Biffinger et al. (2008) examined the effect of $\mathrm{pH}$ on an aerobic miniature $\mathrm{MFC}$ and found 
that $\mathrm{pH}$ not only affected biofilm biomass but, more importantly, the production of a soluble redox mediator, riboflavin. In this study, anode microbial biomass recovered from the FG electrode was greater than that recovered from the other two cells, $2.4 \mathrm{nmol} \mathrm{FA}$ versus 0.9 to $1.4 \mathrm{nmol}$ (Table 2), and this may explain the 1.5- to 2-fold greater OCP observed with the FG cell. However, $\mathrm{pH}$ and specific metabolic functions, discussed below, could equally have influenced biofilm development and influenced electron transport processes. The acquired data only indicate that there was successful colonization of the electrodes in all three soils and that viable mechanisms must have existed for active transfer of electrons to and from the electrodes. Although the mechanisms of electron transfer were not specifically investigated, the bacterial taxonomy of the enriched electrode biofilms was examined in detail.

As indicated above, the recovery of fatty acids from the electrode surfaces of all three soil cells indicated presence of viable microbial biofilms. Fatty acid profiles can provide insight into microbial community abundance and composition and serve as a quantitative measure of community change over time or due to perturbation (Vestal and White 1989). As inocula, all three soils contained a substantial microbial biomass, with little differences being observed top to bottom (Table 2). For the CRL and FW soil cells, the amount of fatty acid recovered from the soils was comparable, averaging 25 to $33 \mathrm{nmol} \mathrm{g}^{-1}$ of soil, respectively, which was slightly greater than that observed in the FG soil, $19 \mathrm{nmol} \mathrm{g}^{-1}$. Assuming 1 pmol of fatty acid is quivalent to $2.5 \times 104$ bacterial cells (Balkwill et al. 1988), we find that then the cell density for the three soils varied from 5 to $8 \times 108$ cells per gram of soil.

\subsection{Anode biofilms}

Although eukaryotic biomarkers were detected on the anode surfaces in all three test cells, this biomass composed less than $10 \%$ of the total microbial biomass recovered (Table 2). This result suggests that electron transfer at the anodes was mediated principally by prokaryotes. We assumed that any prokaryotic biomass that was successful in colonizing an anode surface would show a different composition than that present in the surround soil matrix owing to the stark differences in available substrates. Principal components analysis of the prokaryotic fatty acid profiles indicated that differences existed between the compositions of soil and anode bacterial communities (Fig. 3). Factor variable-correlations for the $1^{\text {st }}$ principal component identified the shift or difference in community composition, 
soil to anode, to be characterized by increased relative percentages of monounsaturated and normal saturated fatty acids (Table 3). A means comparison of specific prokaryotic FA biomarkers indicated that the normal saturated and monousaturated FA were significantly different $(\mathrm{p}<$ 0.05), with the anode biofilms showing the greater relative molar percentages (Fig. 4).

Table 2. Relative molar percentages and absolute abundances of prokaryotic and eukaryotic fatty acid (FA) biomarkers detected in the soils, top middle and bottom fractions, on the electrodes, biofilm and attached soil, and in the catholyte of the three test cells are provided. Biomarker abbreviations are described in the accompanying key.

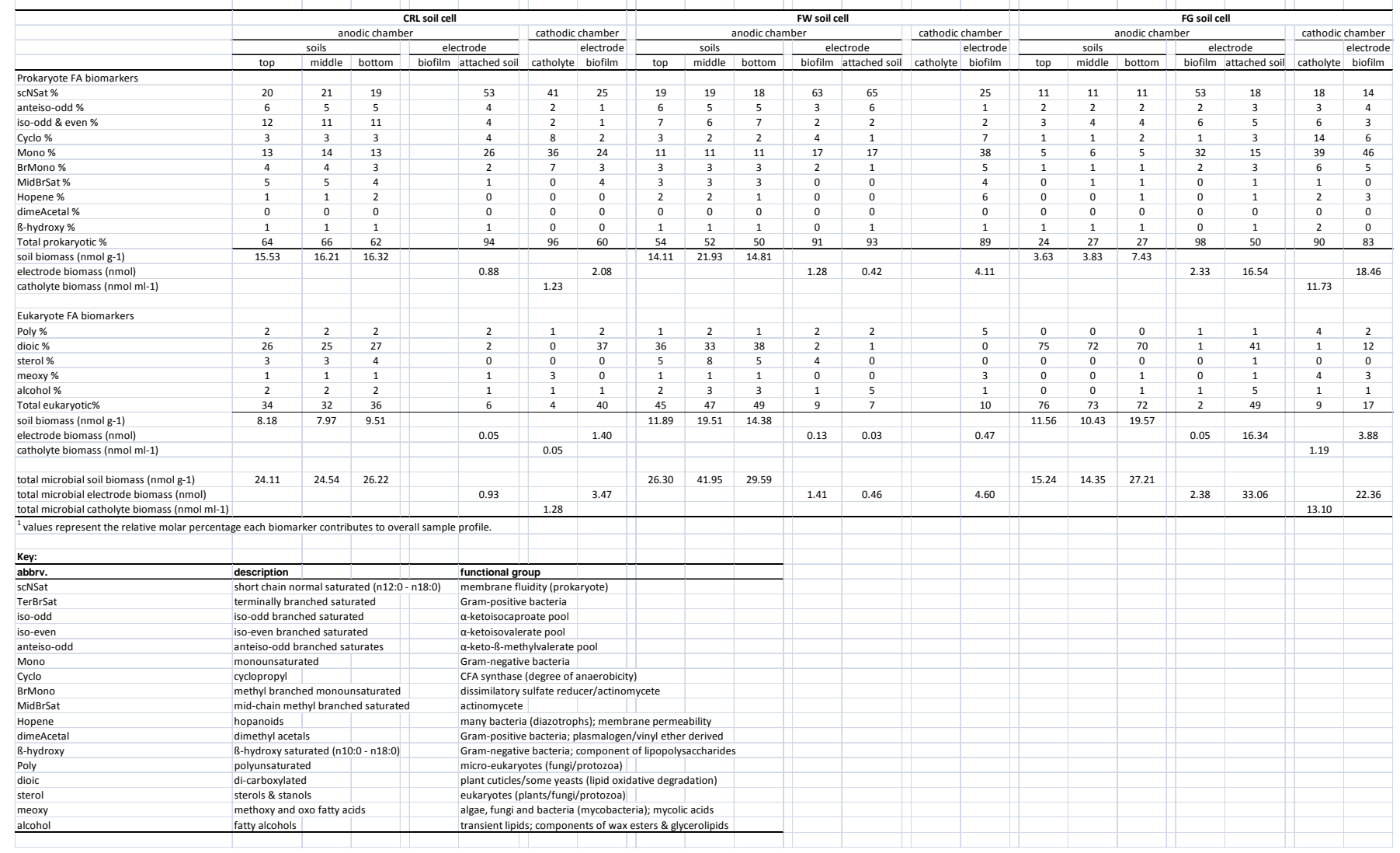

A broad diversity of bacteria has previously been identified in anode biofilms. Proteobacteria, including members of the alpha, beta, gamma, and delta classes, have all been identified as anodophyllic organisms when enriched from a variety of inocula that include wastewaters, sewage sludge, and sediments, (Kim et al. 2004; Phung et al. 2004; Kim et al. 2007; Chung and Okabe 2009). Molecular analysis of 16S rRNA genes have resulted in the identification of Firmicutes (typically Gram-positive) and Actinobacteria (often Gram-variable) on the anodes of fuel cells inoculated with wastewaters (Chung and Okabe 2009; Phung et al. 2004, respectively). Results of the fatty acid analyses performed in this study largely agree 
with these findings in terms of the types of bacteria detected and expand the data to delineate the community of bacteria present in the adjacent soil from that directly composing the anode biofilms.

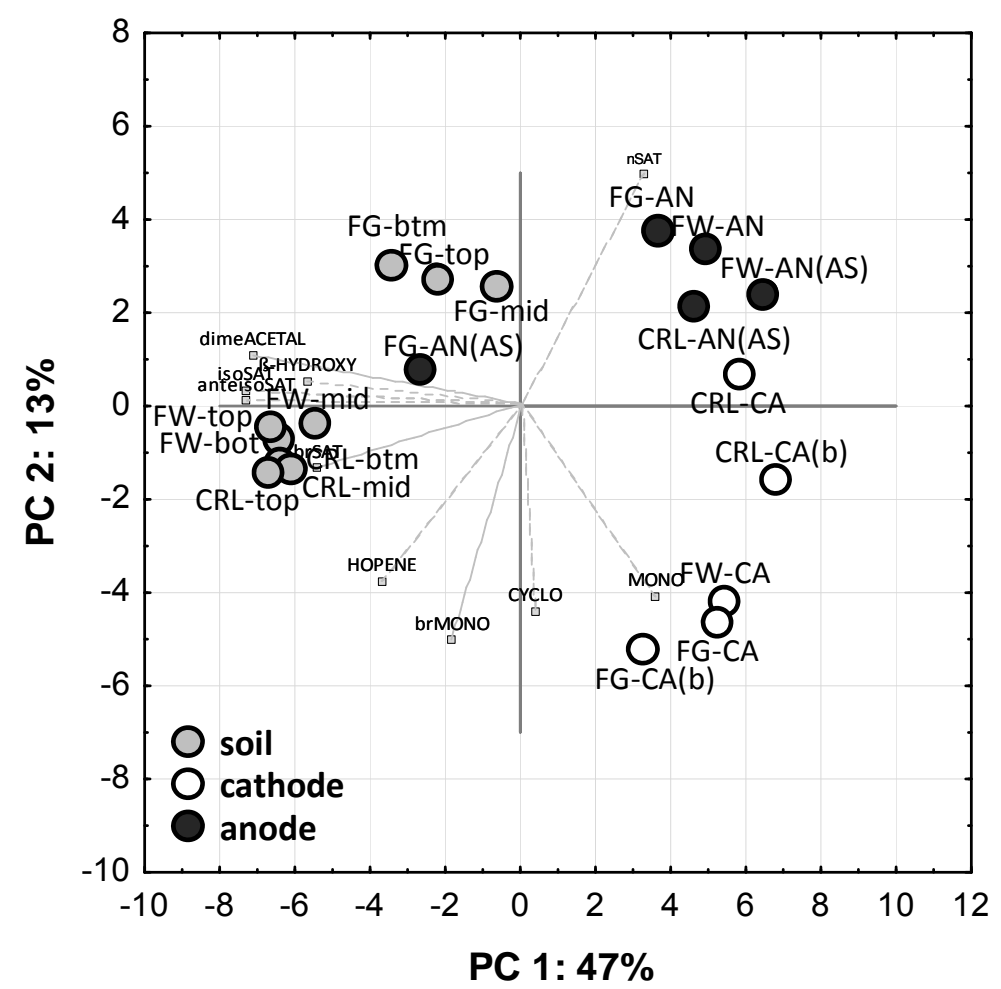

Figure 3. 2D plot illustrating results from the extraction of the $1^{\text {st }}$ two principal components from a dataset comprised of arcsine square root transformed fatty acid molar percentages. Fatty acid profiles recovered from the bulk soil, top, bottom (btm), and middle (mid) fractions, the cathodes, catholyte (b) and cathode biofilm (CA) samples, and the anodes, attached soil (AS) and anode biofilms (AN) for each of the three soil cells, FG, FW, and CRL. The superimposed bi-plot illustrates factor variable correlations (loadings) associated with the first two principal components. The fatty acid functional group abbreviations are described in Table 2. 


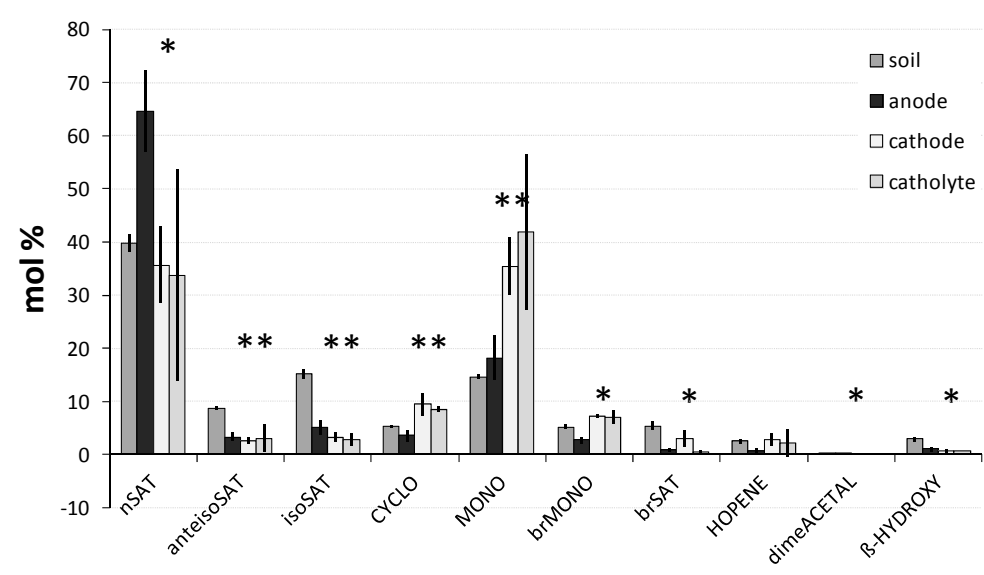

Prokaryotic FA biomarkers

Figure 4. A means comparison of fatty acid methyl ester (FAME) structural class molar percentages (mol\%) across the averaged soil profiles (top, middle and bottom, $n=9$ ), anode attached soils and biofilms $(n=5)$, cathode biofilms $(n=3)$, and catholyte $(n=2)$. A Tukey HSD post hoc comparison of means identified means that differed significantly at $p<0.05(*)$ or $p<0.01(* *)$.

Table 3. Factor variable correlations (loadings) between prokaryotic fatty acid (FA) profiles and the $1^{\text {st }}$ principal component that resulted following the principal components analysis of soil, electrode, and catholyte arcsine square root transformed fatty acid molar percentages.

\begin{tabular}{|l|c|}
\hline \multirow{2}{*}{ Prokaryotic FA biomarkers } & PC1 \\
\hline monounsaturate & $\begin{array}{c}\text { factor-variable } \\
\text { correlations }\end{array}$ \\
\hline normal saturate & 6.20 \\
\hline cyclopropyl & 5.42 \\
\hline $\mathrm{CH}_{4}$ branched mnounsaturate & 0.54 \\
\hline mid-chain $\mathrm{CH}_{4}$ branched saturate & -3.13 \\
\hline hopene & -8.58 \\
\hline ß-hydroxy saturate \& unsaturate & -10.66 \\
\hline iso $\mathrm{CH}_{4}$ branched saturate & -11.84 \\
\hline anteiso $\mathrm{CH}_{4}$ branched saturate & -13.91 \\
\hline
\end{tabular}

Examination of the 16S rRNA gene through terminal restriction fragment length polymorphisms (TRFLP) provided a greater resolution from which anode community similarities and dissimilarities could be determined (Fig. 5). In principle, each terminal restriction fragment (TRF) generated 
from a given restriction digest should represent a unique species of bacteria (Marsh 1999). Although this assumption does not always hold true (Blackwood et al. 2007), TRFLP profiles have been successfully used to fingerprint a targeted community and to make comparisons between communities (for example, Kuehl et al. 2005). With the assumption that each identified TRF represents a unique organism, phylotype richness can be estimated from the number of TRF detected. Results from the anode biofilms indicated a similar richness across the three soil cells, with the CRL anode biofilm showing a slightly greater richness, 58 total detected TRF, compared to both the FG and FW cell anodes, 44 and 40 total TRF, respectively. A direct comparison of anode biofilm TRF profiles for the three soil cells indicated both commonalities and differences. Specific TRF, for example Msp I $476 \mathrm{bp}$, were detected in all three biofilms, suggested the enrichment of a common organism from all three of the soil inocula. Other TRF, for example Rsa I $220 \mathrm{bp}$, were enriched from a single soil cell. Results indicate that the bacterial taxonomy of the three anode biofilms differed as a result of the starting inocula, but also that the enriched biofilms shared some common characteristics.
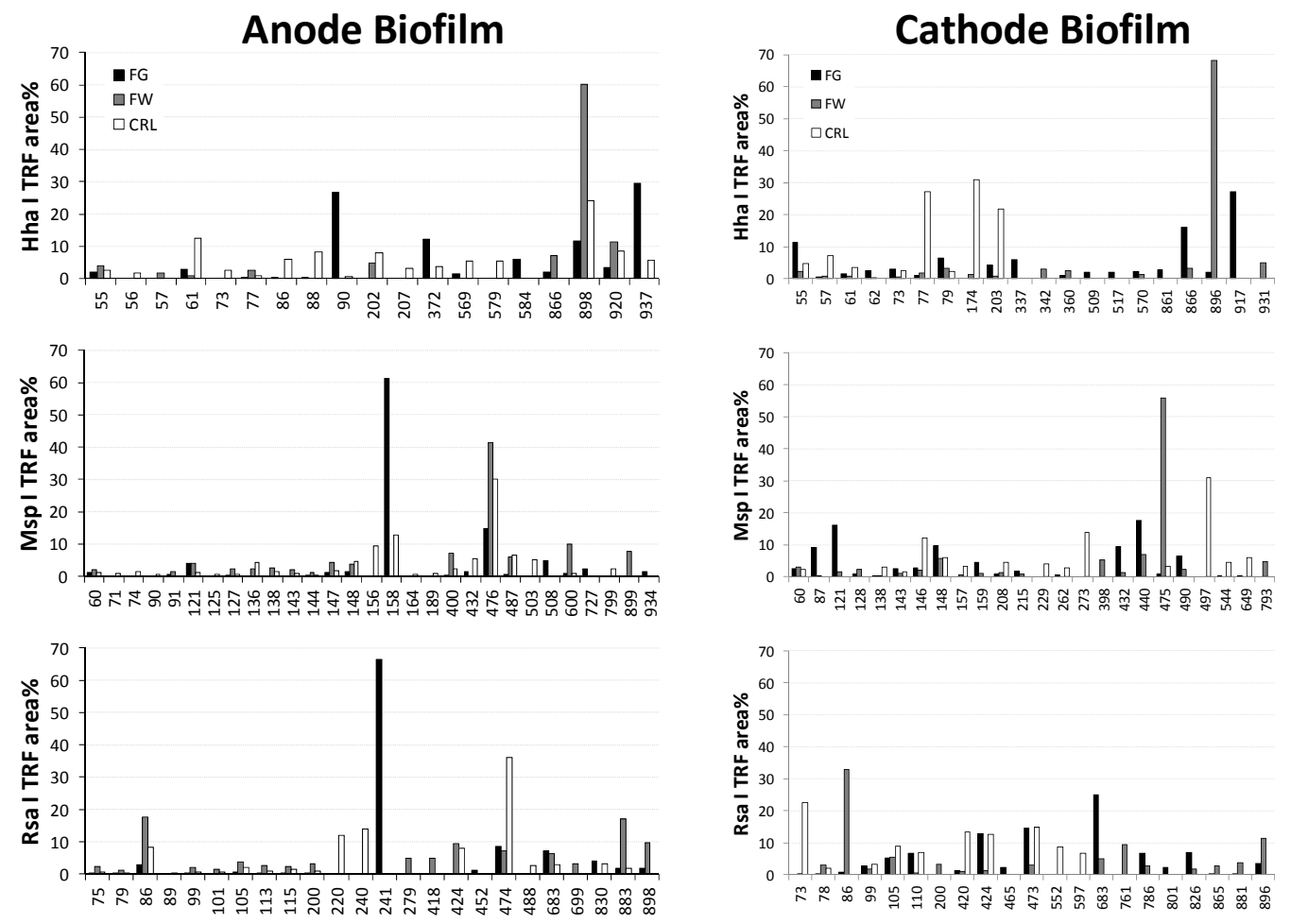

Figure 5. Recovered and retained terminal restriction fragments (TRF) for each of the three soil cells (FG, FW, and CRL) following three restriction digests (Hha I, Msp I, and Rsa I) of bacterial 16S rRNA amplicons of electrode (anode and cathode) biofilm DNA. Each TRF is identified by size as base pairs (bp) and by relative area percentage (area\%). 
In silico digests of the ribosomal database were then performed to assign putative identifications to the recovered TRF (Table 4). Of the identified genera, the $\mathrm{N}_{2}$-fixing Rhizobiales were well represented among all three anode biofilms (Fig. 6). The presence of diazotrophs on anode surfaces has also been reported by others. Ishii et al. (2008a) identified a filamentous anode biofilm community composed of a Rhizobiales that developed from rice paddy soil as an inoculum. A Mesorhizobium sp. was observed, in situ, by Sukkasem et al. (2008) when examining the anode biofilm of a single chamber air cathode MFC inoculated with wastewater. Saito et al. (2010) recently observed that anodes with an $\mathrm{N} / \mathrm{C}$ ratio of 0.7 achieved a greater power density than those with an $\mathrm{N} / \mathrm{C}$ ratio of 3.8 , suggesting that the presence of excess nitrogen, which is inhibitory to bacterial nitrogen fixation, limited the growth or activity of diazotrophs on the anode surface. In this study, the soil cell producing the greatest voltage, FG, also showed the lowest N/C ratio, $\sim 10$ times lower (Table 1 ). In addition to the Rhizobiales, all three biofilms showed evidence for the presence of species of burkholderiales, and rhodobacterales. Studies have identified B-proteobacteria, if not Burkholderia sp. specifically, and other $\alpha$-Proteobacteria such as the Rhodobacterales as members of anode biofilm communities (Phung et al. 2004; Chung and Okabe 2009; Lee et al. 2010). Results from this study indicate that anode colonization by diazotrophic organisms had occurred and that these organisms, Rhizobiales and/or Rhodobacterales likely played an electrogenic role in each of the three soil cells. However, these were not the only organisms putatively identified and, in agreement with the fatty acid analysis, the detection of Firmicutes, Cyanobacteria and $\delta$ Proteobacteria suggests a complexity to the anode bacterial communities.

Both the CRL and FW soil cell anodes yielded putative TRF bacterial identifications that were unique to the particular test cells. Unique to the FW cell anodes was the putative identification of cyanobacteria. Pisciotta et al. (2010) recently demonstrated a light-dependent electrogenic activity in variety of cyanobacteriathat appeared to be fundamentally different from the known electrogenic activity of bacteria. Unique to the CRL cell anode was the putative identification of myxococcales. The $\delta$-proteobacteria have been identified on the anodes of a number of MFC systems, and in particular those operated with wastewaters and under anaerobic conditions. Even though the soil cells in this study were not operated anaerobically, the addition of water to near saturation would have favored the formation of anaerobic niches, such as those that occur at surface-biofilm interface (Bishop and Yu 1999). Although differences in soil chemistry likely affected the 
development of the anode biofilm communities, it is believed that the community composition is also a reflection of the electrogenic nature of the biofilm (Wrighton et al. 2010).

\section{anodes}
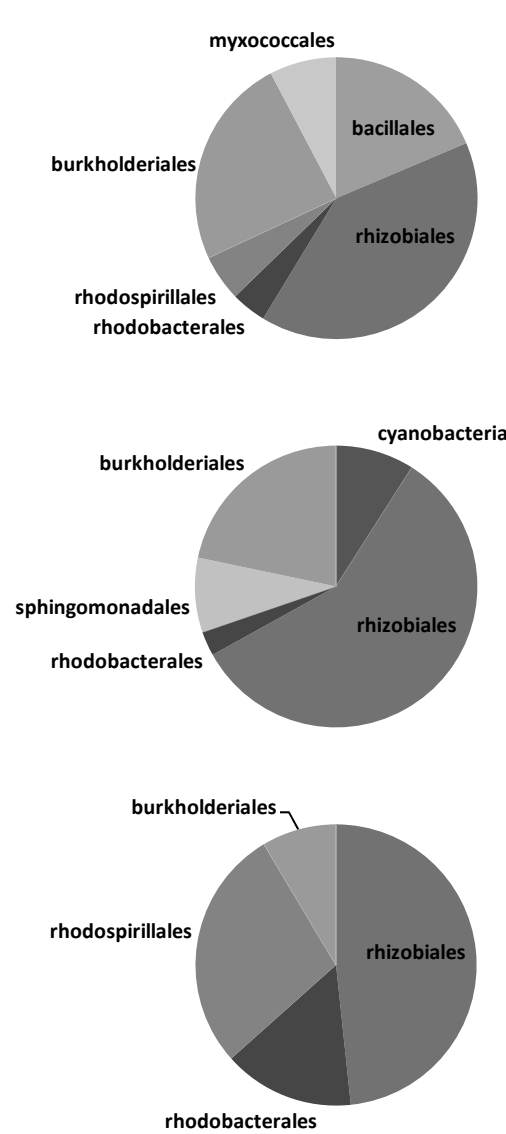

\section{cathodes}
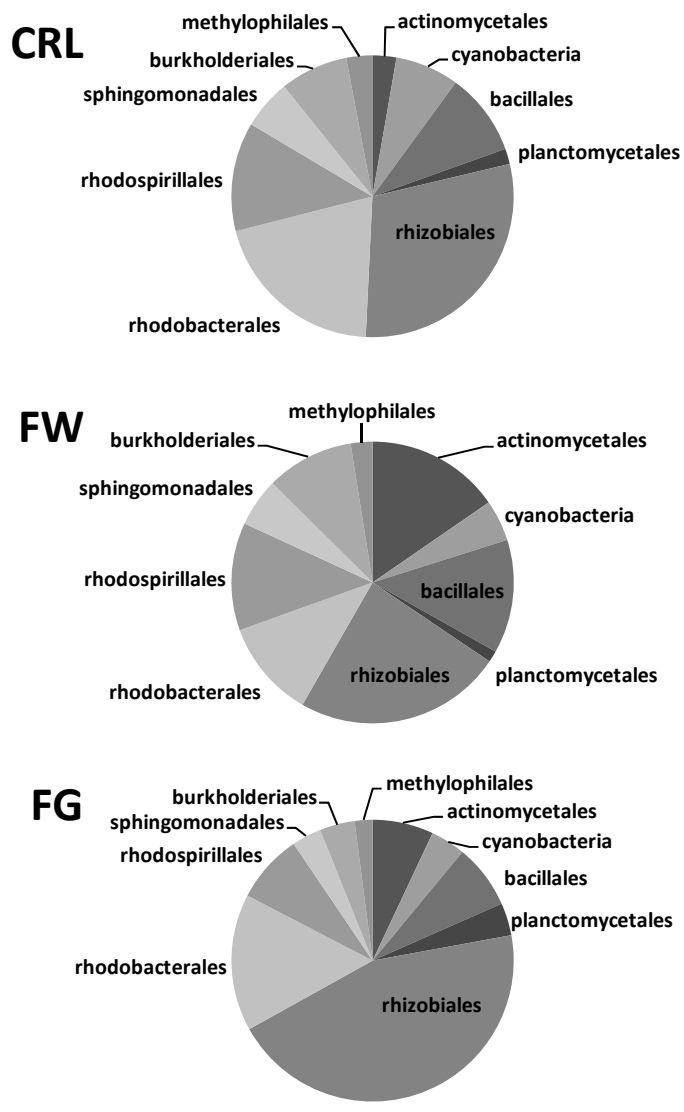

Figure 6. Pie charts of each of the three soil cell anode and cathode biofilm terminal restriction fragments that could be putatively identified through an in silico digest of the ribosomal database. The identified organisms and associated area percentages are provided in Table 4. 
Table 4. Putative identifications for retained terminal restriction fragments of amplified 16S rRNA DNA recovered from the anodes and cathodes of the three test cells following the in silico digest of the ribosomal database. Sample TRF that could be matched to an organism are provided along with the normalized (to $100 \%)$ relative area percentages.

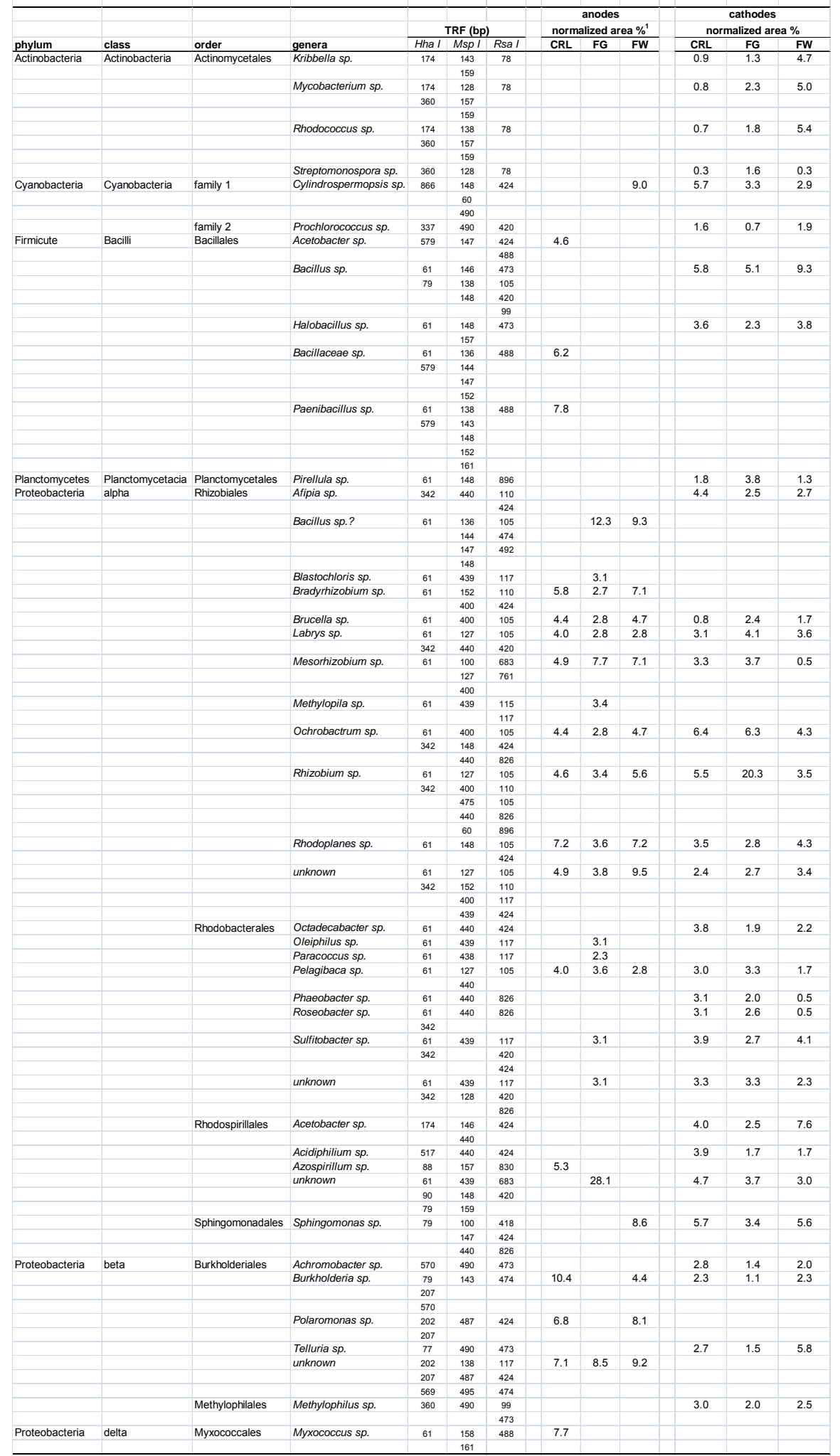


In addition to the above described in situ analyses, we also performed enrichments and isolation to obtain single organisms for future study. Those bacteria susceptible to enrichment, isolation, and identifications are provided in Table 5. All three anodes yielded Burkholderiales, Rhodobacterales, and Bacillales, all in agreement with the TRFLP results. In addition, a large number of Actinomycetals were isolated from the anode biofilms. Unfortunately, the lack of enrichment of Rhizobiales may reflect a bias attributable to media formulations and/or culture conditions. Never-the-less, the in situ community analyses by FA indicated an enrichment in monounsaturated FA onto anode surfaces, which are representative of Gram-negative bacteria such as the Proteobacteria. The in situ analysis by TRFLP also putatively identified the presence of Proteobacteria on the anode surfaces of all three test cells. Lastly, species of $\alpha$ - and $\beta$-Proteobacteria were enriched and isolated from the anode surfaces. Voltage output from the FG soil cell was approximately 2-fold greater than that of either the FW or CRL cells. Under the assumption that the electrogenic nature of the biofilms is reflected by the extant community composition, then the FG anode surface should show a distinguishing characteristic.

The relative percentage of monounsaturated FA from the FG biofilm, $32 \%$, was slightly greater than that extracted from either the FW, $17 \%$, or the CRL, 26\%, anode biofilms (Table 2). The relative percentage of FG biofilm TRF putatively identified as being from $\alpha$-Proteobacteria, 92\%, was far greater than those recovered from the FW or CRL biofilms, 69 and $49 \%$, respectively (Table 4). In contrast, TRF putatively identified as belonging to $\beta$-Proteobacteria were detected at only $8 \%$ in the FG biofilm compared to 22 and $32 \%$ in the FW and CRL biofilms. A similar result was also seen with the percentage of TRF putatively identified as belonging to Firmicutes. The results are consistent in identifying the $\alpha$-Proteobacteria as substantial colonizers of graphite anodes and suggest that their abundance is directly related to the electrogenic capacity of the anodes. 
Table 5. Enriched, isolated, and identified bacteria recovered from the anode and cathode biofilms of each of the three test cells. Bacteria were identified by fatty acid profile using the Sherlock identification system.

\begin{tabular}{|c|c|c|c|c|c|c|c|}
\hline soil & isolate ID & electrode & Identification & index & phylum & class & order \\
\hline \multirow[t]{9}{*}{ FG } & i17 & anode(attached) & Kocuria-kristinae & 0.697 & Actinobacteria & Actinobacteria & Actinomycetales \\
\hline & ¡18 & anode(attached) & Bacillus-cereus-GC subgroup A & 0.823 & Firmicute & Bacilli & Bacillales \\
\hline & i26 & anode(loose) & Kocuria-kristinae & 0.724 & Actinobacteria & Actinobacteria & Actinomycetales \\
\hline & $\mathrm{i} 25$ & anode(loose) & Bacillus-mycoides-GC subgroup A (Bacillus cereus group) & 0.651 & Firmicute & Bacilli & Bacillales \\
\hline & $\mathrm{i} 27$ & anode(loose) & Paenibacillus-polymyxa (Bacillus) & 0.746 & Firmicute & Bacilli & Bacillales \\
\hline & $\mathrm{i} 28$ & anode(loose) & Brevundimonas-vesicularis (Pseudomonas vesicularis) & 0.309 & Proteobacteria & a-proteobacteria & Caulobacterales \\
\hline & $\mathrm{i} 23$ & cathode & Arthrobacter-globiformis-GC subgroup A (some 48h) & 0.565 & Actinobacteria & Actinobacteria & Actinomycetales \\
\hline & i21 & cathode & Kocuria-kristinae & 0.706 & Actinobacteria & Actinobacteria & Actinomycetales \\
\hline & $\mathrm{i} 22$ & cathode & Micrococcus-luteus-GC subgroup B (includes ATCC 9341) & 0.619 & Actinobacteria & Actinobacteria & Actinomycetales \\
\hline \multirow[t]{15}{*}{ FW } & i39 & anode(attached) & Arthrobacter-oxydans & 0.646 & Actinobacteria & Actinobacteria & Actinomycetales \\
\hline & i35 & anode(attached) & Rhodococcus-erythropolis/R.globerulus/N.globerula & 0.952 & Actinobacteria & Actinobacteria & Actinomycetales \\
\hline & i36 & anode(attached) & Bacillus-cereus-GC subgroup A & 0.715 & Firmicute & Bacilli & Bacillales \\
\hline & i31 & anode(attached) & Bacillus-megaterium-GC subgroup $A$ & 0.908 & Firmicute & Bacilli & Bacillales \\
\hline & $\mathrm{i} 40$ & anode(attached) & Brevibacillus-parabrevis-GC subgroup B & 0.460 & Firmicute & Bacilli & Bacillales \\
\hline & i32 & anode(attached) & Paracoccus-denitrificans & 0.461 & Proteobacteria & a-proteobacteria & Rhodobacterales \\
\hline & i52 & anode(loose) & Arthrobacter-oxydans & 0.847 & Actinobacteria & Actinobacteria & Actinomycetales \\
\hline & i48 & anode(loose) & Kocuria-kristinae & 0.880 & Actinobacteria & Actinobacteria & Actinomycetales \\
\hline & i45 & anode(loose) & Bacillus-megaterium-GC subgroup A & 0.803 & Firmicute & Bacilli & Bacillales \\
\hline & i51 & anode(loose) & Brevibacillus-parabrevis-GC subgroup B & 0.769 & Firmicute & Bacilli & Bacillales \\
\hline & i47 & anode(loose) & Janthinobacterium-lividum & 0.836 & Proteobacteria & ß-proteobacteria & Burkholderiales \\
\hline & $i 49$ & anode(loose) & Paracoccus-denitrificans & 0.619 & Proteobacteria & a-proteobacteria & Rhodobacterales \\
\hline & i43 & cathode & Microbacterium-flavescens (Aureobacterium, Arthrobacter) & 0.059 & Actinobacteria & Actinobacteria & Actinomycetales \\
\hline & i44a,b & cathode & Micrococcus-luteus-GC subgroup A & 0.222 & Actinobacteria & Actinobacteria & Actinomycetales \\
\hline & $\mathrm{i} 42$ & cathode & Stenotrophomonas-maltophilia (Xanthomonas, Pseudomonas) & 0.165 & Proteobacteria & ?-proteobacteria & Xanthomonadales \\
\hline \multirow[t]{6}{*}{ CRL } & i1 & anode(attached) & Bacillus-cereus-GC subgroup A & 0.352 & Firmicute & Bacilli & Bacillales \\
\hline & i5 & anode(attached) & Ralstonia-eutropha (Alcaligenes eutrophus) & 0.946 & Proteobacteria & ß-proteobacteria & Burkholderiales \\
\hline & i16 & anode(loose) & Bacillus-cereus-GC subgroup $A$ & 0.610 & Firmicute & Bacilli & Bacillales \\
\hline & ¡12 & cathode & Arthrobacter-globiformis-GC subgroup A (some $48 \mathrm{~h}$ ) & 0.366 & Actinobacteria & Actinobacteria & Actinomycetales \\
\hline & i10 & cathode & Kocuria-kristinae & 0.684 & Actinobacteria & Actinobacteria & Actinomycetales \\
\hline & i9 & cathode & Microbacterium-barkeri (Aureobacterium, Corynebacterium) & 0.654 & Actinobacteria & Actinobacteria & Actinomycetales \\
\hline
\end{tabular}

\subsection{Cathode Biofilms}

Biocathodes facilitate the efficient reduction of oxygen within the cathodic chamber and the composition of cathode biofilms can also reflect the performance of an MFC (Clauwaert et al. 2007). Wrighton et al. (2010) determined that bacterial community structure of cathode biofilms corresponded to MFC performance and that $\alpha$ - and $\gamma$-Proteobacteria, and Firmicutes, made up a large percentage of the cathode community. In contrast to this study, the cathode communities described by Wrighton et al. (2010) were initiated from wastewater treatment sludge and propagated in a minimal nutrient media. Considering that no nutrient supplements were added to the cathodic chamber in this study, other than the small aliquot of soil, the presence of any biofilm at all suggests a selective enrichment of bacteria capable of using the cathode, at least in part, as a source of electrons.

Fatty acid profiles and abundances in the catholyte and cathode biofilms were found to be similar, which is attributed to the restrictive nature of the 
growth media present in the cathode chamber (Fig. 3 and 4). Cathode biofilms also showed a diversity of prokaryotic FA, which was composed primarily of monounsaturated FA and to lesser extents by terminally branched and mid-chain branched saturated FA, a similar result to that observed with the anode biofilms. The diversity of FA detected on the cathodes suggests some complexity to the composition of these biofilm communities, which was similar in nature to that described for the anode biofilms. However, the two electrode biofilms did differ substantially in the amount of eukaryotic biomass detected, which constituted between 10 and $40 \%$ of total cathode biofilm microbial biomass (Table 2). Of the eukaryotic functional groups detected, dioic fatty acids, which are indicative of some yeasts, were prominent in both the CRL and FG soil cells. Yeasts have been shown to mediate electron transfer to MFC anodes and are considered by some to be ideal electrogenic organisms owing to their growth rates and broad spectrum for substrates (Gunawardena et al. 2008; Ganguli and Dunn 2009; Haslett et al. 2011). Neither molecular nor enrichments/isolations were performed to further identify any cathode eukaryotes; however, the presumed presence of higher organisms on the cathodes suggests that these organisms may have played a role in mediating electron transfer from the electrodes.

Bacterial communities on the cathodes were also further evaluated through TRFLP analysis of amplified 16S rRNA gene fragments. Unexpectedly, TRF recovered from the biocathodes indicated a phylotype richness that was 14-20\% greater than that observed on the respective anodes in the FG and FW cells, but $45 \%$ lower in the CRL cell (Fig. 5). The formation of similar, but not identical, biofilms on both anodes and cathodes was not anticipated. We assumed that the prevalence of carbon substrates present in the soils surrounding the anode electrodes would produce a biofilm considerably different from that forming on the cathodes. The finding of similar communities on both electrodes suggests a specific influence of the graphite surfaces on biofilm formation. Although the catholyte was not augmented with nutrients or carbon substrates other than that present in the initial inoculums, the results of both the FA and TRFLP assays indicate that conditions within the cathodic chamber were sufficient to support the growth of a biofilm as or more complex than that observed on the corresponding soil embedded anodes.

A number of recovered TRF could also be putatively assigned to bacterial species (Table 4). Rhizobiales, Rhodobacterales, Rhodospirillales, 
Burkholderiales, and Bacillales were prominent in each of the three cathode biofilms. These are the same orders that were found to be prominent in the anode biofilms. In addition, Actinomycetales were putatively identified in each of three biofilms and these were the only order of bacteria, other than a single $\gamma$-Proteobacteria, that were susceptible to enrichment and isolation from the cathode biofilms (Table 5). Of the cultured Actinomycetales, species of Arthobacter and Micrococcus have been identified as electrogenic and effectively used as anode inocula (Hou et al. 2011; Choi et al. 2007). Although Wrighton et al. (2010) did identify the presence of actinobacteria on a biocathode, these organisms were not found to be predominant, a finding similar to this study. These non-spore forming cocci are both chemoorganotrophic and usually grow on simple media. Their ability to utilize a variety of substrates for metabolism likely enabled their colonization of the soil cell cathodes.

The presence of diazotrophs on both the anodes and cathodes may suggest a dual role for these organisms. As discussed above, Saito et al. (2010) suggested that lower $\mathrm{N} / \mathrm{C}$ ratios at the anode could translate into greater MFC power densities. We also observed a greater voltage output in a soil cell that exhibited a low N/C ratio. However, N/C ratios at the cathodes should have been similar for all three cells because of the consistency of bulk media type and the minimal amount, $0.1 \mathrm{~g}$, of soil added. As the catholyte was not amended with organic nitrogen, the ability to fix atmospheric nitrogen would have been advantageous to organisms within the cathode biofilm. Nitrogen fixing activity at the cathode, as evidenced by the putative identification of Rhizobiales, could have made a product for subsequent nitrification and denitrification. Although nitrifiers were not specifically identified from the in silco digests, potential denitrifying populations were. Similar to the result of Wrighton et al. (2010), members of the Burkholderiales and Bacillales were prominent on the cathodes of all three test cells examined in this study. It is possible that the diversity of organisms putatively identified on the cathodes describes a complex community that supports a coupled nitrogen cycle, one that ultimately facilitates the reduction of oxygen at the electrode surface. 


\section{Summary and Conclusion}

The simple cells proved to be sufficient test vessels for examining the development of anodophyllic and cathodophyllc soil organisms. The recovery of a microbial biomass from both anodes and cathodes and the identification of community differences between the inocula and the biofilms that formed indicated that a selective enrichment had occurred. The measurement of an electrical output suggested that these enriched biofilms were, at least partially, electrogenic in nature. Polyphasic analysis of anode biofilm taxonomy identified an enrichment of Proteobacteria, specifically aProteobacteria. In situ analyses indicated a predominance of Rhizobiales and differences in soil geochemistry, specifically the N/C ratios, suggested a correlation between the abundance of these organisms and the electrogenic capacity of the anode biofilms. In the cathode chamber, the diversity in situ biomarkers detected in the electrode biofilms suggested some complexity to the composition of these biofilm communities that was not only similar in nature to that of the anode biofilms, but also of greater phylotype richness. One distinguishing characteristic of the cathode biofilms was an abundance of an eukaryotic biomass, specifically one attributed to yeasts. Results of this study identified the existence of complex biofilms on both anodes and cathodes. The diversity and types of organisms identified on the electrode surfaces in this study were similar to the findings of others, and as a whole these results suggest that the turnover of nitrogen at the electrode surfaces, anode or cathode, can play a significant role in MFC function. 


\section{References}

Alterman, P., K. Rabaey, P.Clauwaert, and W. Verstraete. 2006. Microbial fuel cells for wastewater treatment. Wat. Sci. Technol. 54(8): 9-15.

Balkwill D. L, F. R Leach, J. T. Wilson, J. F. McNabb, and D. C. White. 1988. Equivalence of microbial biomass measures based on membrane lipid and cell wall components, adenosine triphosphate, and direct counts in subsurface sediments. Microb Ecol. 16: 73-84.

Biffinger, J. C., J. Pietron, O. Bretschger, L. J. Nadeau, G. R. Johnson, C. C. Willimas, K. H. Nealson, and B. R. Ringeisen. 2008. The influence of acidity on microbial fuel cells containing Shewanella oneidensis. Biosens. Bioelectron. 24(4): 906-911.

Bishop, P. L., and T. Yu. 1999. A microelectrode study of redox potential change in biofilms. Wat. Sci. Technol. 39(7): 179-185.

Blackwood, C. B., D. Hudleston, D. R. Zak, and J. S. Buyer. 2007. Interpreting ecological diversity indices applied to terminal restriction fragment length polymorphism data: Insights from simulated microbial communities. Appl. Environ. Microbiol. 73(16): 5276-5283.

Chaudhuri, S. K., and D. R. Lovely. 2003. Electricity generation by direct oxidation of glucose in mediatorless microbial fuel cells. Nature Biotech. 21(10): 1229-1232.

Choi, Y., E. Jung, H. Park, S. Jung, and S. Kim. 2007. Effect of initial carbon sources on the performance of a microbial fuel cell containing environmental microorganism micrococcus luteus. Notes 28: 1591.

Chung, K., and S. Okabe. 2009. Continuous power generation and microbial community structure of the anode biofilms in a three-stage microbial fuel cell system. Appl. Microbiol. Biotechnol. 83: 965-977.

Clauwaert, P., D. Van Der Ha, N. Boon, K. Verbeken, M. Verhaege, K. Rabaey, and W. Verstraete. 2007. Open air biocathode enables effective electricity generation with microbial fuel cells. Environ. Sci. Technol.

Dunbar, J., L. O. Ticknor, and C. R. Kuske. 2000. Phylogenetic specificity and reproducibility and new method for analysis of terminal restriction fragment profiles of $16 \mathrm{~S}$ rRNA genes from bacterial communities. Appl. Environ. Microbiol. 67(1): 190-197.

Ganguli, R., and B. S. Dunn. 2009. Kinetics of anode reactions for a yeast-catalysed microbial fuel cell. Fuel Cells 9: 44-52.

Gunawardena, A., S. Fernando, and F. To. 2008. Performance of a yeast-mediated biological fuel cell. Int. J . Mol. Sci. 9(10): 1893-1907.

Haslett, N. D., F. J. Rawson, F. Barriere, G. Kunze, N. Pasco, R. Gooneratne, and K. H. Baronian. 2011. Characterization of yeast microbial fuel cell with the yeast Arxula adeninivorans as the biocatalyst. Biosens. Bioelectron. Epub ahead of print. 
Hou, H., L. Li, P. de Figueiredo, and A. Han. 2011. Air-cathode microbial fuel cell array: a device for identifying and characterizing electrochemically active microbes. Biosens. Bioelectron. 26(5): 2680-2684.

Ishii, S., T. Shimoyama, Y. Hotta, and K. Watanabe. 2008a. Characterization of a filamentous biofilm community established in a cellulose-fed microbial fuel cell. BMC Microbiol 8: 6 .

Ishii, S., Y. Hotta, and K. Watanabe. 2008b. Methanogenesis versus electrogenesis: morphological and phylogenetic comparisons of microbial communities. Biosci Biotechnol. Biochem. 72(2): 286-294.

Jiang, D., B. Li, W. Jia, and Y. Lei. 2010. Effect of inoculum types on bacterial adhesion and power production in microbial fuel cells. Appl. Biochem. Biotechnol. 160: 182-196.

Kim, B. H., H. S. Park, H. J. Kim, G. T. Kim, I. S. Chang, J. Lee, and N. T. Phung. 2004. Enrichment of microbial community generating electricity using a fuel-cell-type electrochemical cell. Appl. Microbiol. Biotechnol. 63: 672-681.

Kim, J.R., S. H. Jung, J. M. Regan, and B. E. Logan. 2007. Electricity generation and microbial community analysis of alcohol powered microbial fuel cells. Bioresource Tech. 98: 2568-2577.

Kroppenstedt, R. M. 1985. Fatty acid and menaquinone analysis of actinomycetes and related organisms. In: Chemical Methods in Bacterial Systematics (M.

Goodfellow and D. E. Minnikin, Eds). SAB Technical Series 20, Academic Press, London, pp. 173-199.

Kuehl, C. J., H. D. Wood, T. L. Marsh, T. M. Schmidt, and V. B. Young. 2005. Colonization of the cecal mucosa by Helicobacter hepaticus impacts the diversity of the indigenous microbiota. Infect. Immun. 73(10): 6952-6961.

Lee, T. K., T. V. Doan, K. Yoo, S. Choi, C. Kim, and J. Park. 2010. Discovery of commonly existing anode biofilm microbes in two different wastewater treatment MFCs using FLX Titanium pyrosequencing. Appl Microbiol. Biotechnol. 87: 23352343 .

Liu, H., and B. E. Logan. 2004. Electricity generation using an air-cathode single chamber microbial fuel cell in the presence and absence of a proton exchange membrane. Environ. Sci. Tecnol. 38: 4040-4046.

Liu, W., A. Wang, S. Cheng, B. E. Logan, H. Yu, Y. Deng, J. D. Van Nostrand, L. Wu, Z. He, and J. Zhou. 2010. Geochip-based functional gene analysis of anodophilic communities in microbial electrolysis cells under different operational modes. Environ. Sci. Technol. 44: 7729-7735.

Marsh, T. L. 1999. Terminal restriction fragment length polymorphism (T-RFLP): An emerging method for characterizing diversity among homologous populations of amplification products. Curr. Opin. Microbiol. 2: 323-327.

O’Leary, W. M., and S. G. Wilkinson. 1988. Gram-positive bacteria. In: Microbial Lipids (C. Ratledge and S. G. Wilkinson Eds) Volume 1. Academic Press, p. 117-185. 
Oliveros, J. C. 2007. VENNY. An interactive tool for comparing lists with Venn Diagrams. http://bioinfogp.cnb.csic.es/tools/venny/index.html.

Pham, T. H., N. Boon. P. Aelterman, P. Clauwaert, L. D. Schamphelaire, L. Vanhaecke, K. D. Maeyer, M. Höfte, W. Verstraete, and K. Rabaey. 2008. Metabolites produced by Pseudomonas sp. enable a Gram-positive bacterium to achieve extracellular electron transfer. Appl. Microbiol. Biotechnol. 77: 1119-1129.

Phung, N. T., J. Lee, K. H. Kang, I. S. Chang, G. M. Gadd, and B. H. Kim. 2004. Analysis of microbial diversity in oligotrophic microbial fuel cells using $16 \mathrm{~S}$ rDNA sequences. FEMS Microbiol. Let. 233: 77-82.

Pisciotta, J. M., Y. Zou, and I. V. Baskakov. 2010. Light-dependent electrogenic activity of cyanobacteria. PLoS ONE 5(5): e10821.

Potter, M. C. 1912. Electrical effects accompanying the decomposition of organic compounds. Proc Roy Soc (London) 84(B): 260-276.

Rabaey, K., N. Boon, S. D. Siciliano, M. Verhaege, and W. Verstraete. 2004. Biofuel cells select for microbial consortia that self-mediate electron transfer. Appl Environ, Microbiol, 70(9): 5373-5382.

Rabaey, K., N. Boon, M. Hofte, and W. Verstraete. 2005. Microbial phenazine production enhances electron transfer in biofuel cells. Environ. Sci. Technol. 39:

3401-3408.

Reguera, G., K. D. McCarthy, T. Mehta, J.S. Nicoll, M. T. Tuominen, and D. R. Lovely. 2005. Extracellular electron transfer via microbial nanowires. Nature. 435: 1098-1101.

Ringeisen, B. R., E. Henderson, P. K. Wu, J. Pietron, R. Ray, B. Little, J. C. Biffinger, and J.M. Jones-Meehan. 2006. High power density from a minature microbial fuel cell using Shewanella oneidensis DSP10. Environ. Sci. Technol. 40: 2629-2634.

Saito, T., M. Mehanna, X. Wang, R. D. Cusick, Y. Feng, M. A. Hickner, andB. E. Logan. 2010. Effect of nitrogen addition on the performance of microbial fuel cell anodes. Bioresource Tech. 102: 395-398.

Schamphelaire, L. D., A. Cabezas, M. Marzorati, M. W. Friedrich, N. Boon, and W. Verstraete. 2010. Microbial community analysis of anodes from sediment microbial fuel cells powered by rhizodeposits of living rice plants. Appl Environ. Microbiol. 76(6): 2002-2008.

Schamphelaire, L. D., L. Van Den Bossche, H.S. Dang, M. Hofte, N. Boon, K. Rabaey, and W. Verstraete. 2008. Microbial fuel cells generating electricity from rhizodeposits of rice plants. Environ. Sci. Technol. 42: 3053-3058.

Shantaram, A., H. Beyenal, R. Raajan, A. Veluchamy, and Z. Lewandowski. 2005. Wireless sensors powered by microbial fuel cells. Environ. Sci. Technol. 39: 5037-5042.

Shyu, C., T. Soule, S. J. Bent, J. A. Foster, and L. J. Forney. 2007. MiCA: A web-based tool for the analysis of microbial communities based on terminal-restriction fragment length polymorphisms of $16 \mathrm{~S}$ and $18 \mathrm{~S}$ rRNA genes. J . Microb. Ecol. 53: 562-570. 
Sukkasema, C., S. Xua, S. Parka, B. Boonsawang, and H. L. Sukkasem. 2008. Effect of nitrate on the performance of single chamber air cathode microbial fuel cells. Wat. Res. 42(19): 4743-4750.

Vestal, J. R., and D. C. White. 1989. Lipid analysis in microbial ecology: Quantitative approaches to the study of microbial communities. BioScience, 39(8): 535-541.

White, D. C., and D. B. Ringelberg. 1998. Signature lipid biomarker analysis. In: Techniques in Microbial Ecology (R. S. Burlage, R. Atlas, D. Stahl, G. Geesey, and G. Sayler Eds). New York: Oxford University Press, Inc., p. 255-272.

Wrighton, K. C., B. Virdis, P. Clauwaert, S. T. Read, R. A. Daly, N. Boon, Y. Piceno, G. L. Andersen, J.D. Coates, and K. Rabaey. 2010. Bacterial community structure corresponds to performance during cathodic nitrate reduction. ISME J . 4: $1443^{-1455 .}$

Wilkinson, S. G. 1988. Gram-negative bacteria, In: Microbial Lipids (C. Ratledge and S. G. Wilkinson Eds) Volume 1. Academic Press, p. 299-457. 


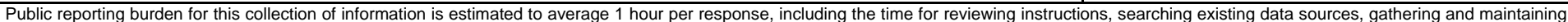

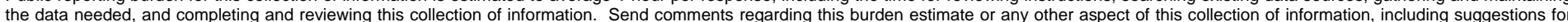

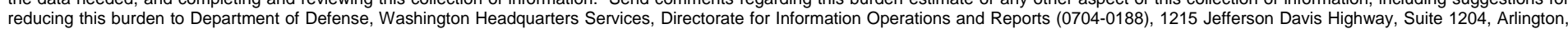

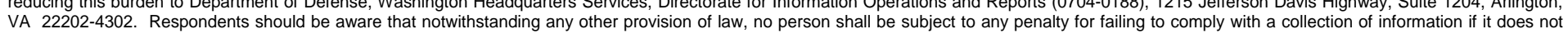
display a currently valid OMB control number. PLEASE DO NOT RETURN YOUR FORM TO THE ABOVE ADDRESS.
1. REPORT DATE (DD-MM-YYYY)
2. REPORT TYPE
3. DATES COVERED (From - To)

April 2012

4. TITLE AND SUBTITLE

Community Composition of Bacterial Biofilms Formed on Simple Soil Based

Bioelectrochemical Cell Anodes and Cathodes

5a. CONTRACT NUMBER

5b. GRANT NUMBER

5c. PROGRAM ELEMENT NUMBER

6. AUTHOR(S)

5d. PROJECT NUMBER

David B. Ringelberg, Karen L. Foley, and Charles M. Reynolds

5e. TASK NUMBER

5f. WORK UNIT NUMBER

7. PERFORMING ORGANIZATION NAME(S) AND ADDRESS(ES)

8. PERFORMING ORGANIZATION REPORT NUMBER

Cold Regions Research and Engineering Laboratory

U.S. Army Engineer Research and Development Center

ERDC/CRREL TR-12-2

72 Lyme Road

Hanover, NH 03755

9. SPONSORING I MONITORING AGENCY NAME(S) AND ADDRESS(ES)

10. SPONSOR/MONITOR'S ACRONYM(S)

Installation Technology Program

U.S, Army Corps of Engineers

11. SPONSOR/MONITOR'S REPORT NUMBER(S)

\section{DISTRIBUTION / AVAILABILITY STATEMENT}

Approved for public release; distribution is unlimited.

\section{SUPPLEMENTARY NOTES}

\section{ABSTRACT}

Microbial fuel cells (MFC), as bioelectrochemical systems, hold promise as a sustainable source of energy for use in novel environments and settings. Although electrode biofilms, both anode and cathode, are critical to the production of power in these systems, the taxonomies of the biofilms that form are not fully understood. The specific objectives of the current study were to classify the bacteria that enriched onto fuel cell electrodes, with three biogeochemically distinct surface soils serving as the inocula. Following 1000 hours of incubation under saturated soil conditions, the community composition of the anode and cathode bacterial biofilms was quantified by culture, fatty acid profile (FA), and terminal restriction fragment length polymorphisms (TRFLP). The three soils produced open circuit voltages of between 60 and $120 \mathrm{mV}$, but only one soil maintained voltage under resistance $(60 \mathrm{mV}$ at 10,000 $\Omega$ ). Fatty acid profiling identified differences among anode, cathode, and bulk soil microbial communities, specifically a greater relative abundance of terminally branched saturated FA in the bulk soils and a greater relative abundance of monounsaturated and cyclopropane FA on electrode surfaces. Bacteria cultured from both the anode and cathode biofilms included species of Actinobacteria; however, only the anode biofilms produced species of Firmicutes and Proteobacteria. Analysis of TRFLP profiles putatively identified a diversity of bacteria in the biofilms recovered from both electrode surfaces. The most predominant organisms detected were the $\alpha$ - and $\beta$-Proteobacteria, specifically the Rhizobiales, Rhodobacterales, and Burkholderiales. Although the detection of similar community fingerprints on both anodes and cathodes was not anticipated, the diversity of organisms putatively identified indicated a complexity that would support a coupled nitrogen cycle, one capable of facilitating the transfer of electrons to the soil cell anodes and from the soil cell cathodes.

\section{SUBJECT TERMS}

Bioelectrochemical cell

Fatty acid profile

16. SECURITY CLASSIFICATION OF:

\section{a. REPORT}

\section{$\mathrm{U}$}

Microbial community composition

\section{TRFLP}

\begin{tabular}{c|c}
$\begin{array}{c}\text { 17. LIMITATION } \\
\text { OF ABSTRACT } \\
\text { none }\end{array}$ & $\begin{array}{c}\text { 18. NUMBER } \\
\text { OF PAGES }\end{array}$ \\
& 35 \\
\hline
\end{tabular}

19a. NAME OF RESPONSIBLE PERSON

19b. TELEPHONE NUMBER (include area code) 